\title{
Fuzzy Delphi Method for Evaluating HyTEE Model (Hybrid Software Change Management Tool with Test Effort Estimation)
}

\author{
Mazidah Mat Rejab ${ }^{1,4}$, Nurulhuda Firdaus Mohd Azmi ${ }^{2}$, Suriayati Chuprat ${ }^{3}$ \\ Razak Faculty of Informatics and Technology, Universiti Teknologi Malaysia, Kuala Lumpur Malaysia ${ }^{1,2,3}$ \\ Faculty of Computer Sciences and Information Technology, Universiti Tun Hussein Onn Malaysia (UTHM), Batu Pahat, Johor ${ }^{1}$
}

\begin{abstract}
When changes are made to a software system during development and maintenance, they need to be tested again i.e. regression test to ensure that changes behave as intended and have not impacted the software quality. This research will produce an automated tool that can help the software manager or a maintainer to search for the coverage artifact before and after a change request. Software quality engineer can determine the test coverage from new changes which can support cost estimation, effort, and schedule estimation. Therefore, this study is intended to look at the views and consensus of the experts on the elements in the proposed model by benefitting the Fuzzy Delphi Method. Through purposive sampling, a total of 12 experts from academic and industrial have participated in the verification of items through 5-point linguistic scales of the questionnaire instrument. Outcome studies show $90 \%$ of elements in the proposed model consists of change management, traceability support, test effort estimation support, regression testing support, report and GUI meet, the value threshold ( $d$ construct) is less than 0.2 and the percentage of the expert group is above $75 \%$. It is shown that elements of all the items contained in the venue are needed in the HyTEE Model (Hybrid Software Change Management Tool with Test Effort Estimation) based on the consensus of experts.
\end{abstract}

Keywords-Fuzzy Delphi Method; software traceability; test effort estimation; regression testing; software changes

\section{INTRODUCTION}

The software application is present in every area of our life. The small and large system is developed using the software. Change is a part of everyday life. Software changes after some time. In today's competitive atmosphere, brand new needs are arising, and existing needs are altering swiftly. Changes are accomplished for various reasons, for example, to include new elements, to amend a few errors or to improve the product.

According to Vasa [1], "Software evolution or changes are direct consequences and reflections of ongoing changes in a dynamic real world". These changes are occurring very fast because of the competitive market. Enhancing software is a common necessity in business today as they encounter lots of need changes, prolonging software features and function, and including brand new modules. We cannot ignore the critically of software changes because real software system changes and becomes more complex over time [1]. A current report distributed by the Standish Group International [2] which involved 13522 software projects, Fig. 1 showed that out of the reviewed projects just 29 percent were effective, 18 percent is considered as "failed" and 53 percent are viewed as "suspected" and the fundamental driver of the failed project is the prerequisite change. Lam [3] propose that changing necessity are the main issues of the re-building and maintenance activities. The majority of the previous study demonstrates that software maintenance activities are concerning adaptive and completeness maintenance close to $80 \%$. For this aim, the company must get the opportunity to manage requirement adaptation as part of the border software evolution approach. One estimate expresses that $40 \%$ of the necessity requirement during software development [4].

Estimation is limited as the shrewd conviction of the quantum or field that should be performed and the essential material (in particular, HR, money related assets, material assets, and time assets) required playing out the work at a future date in a characterized domain for determined strategies. Test Effort Estimation that estimate of the testing length, exertion, cost and timetable for a specific programming test project in an individual domain for particular strategies, tool and methods [6]. The test effort is the foundation of the effort spent on test action and the effort spent on debug action [7].

Research objective for this study is:

1) To develop a software traceability model to reduce operational cost during regression testing using the Fuzzy Delphi Method.

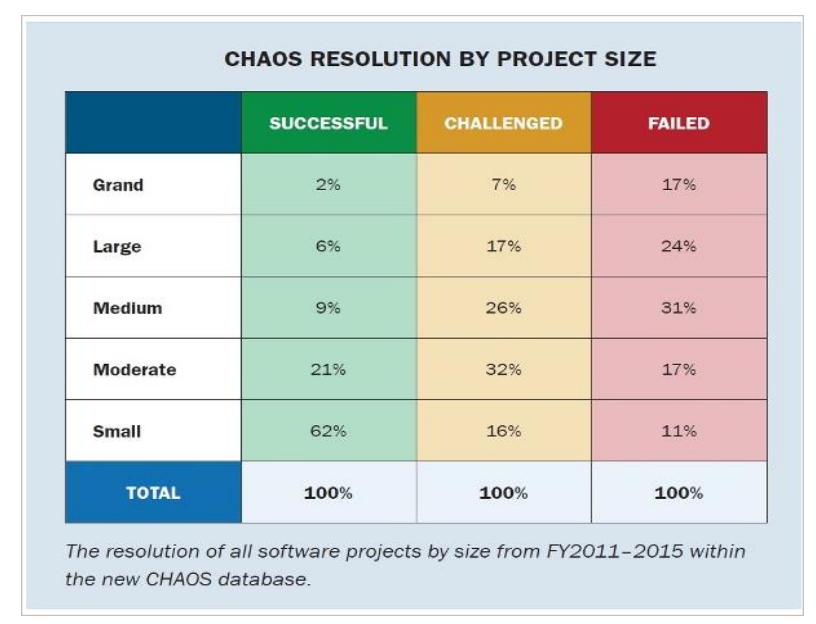

Fig. 1. CHAOS Resolution by Project Size 2011-2015 [5]. 
This study utilizes the FDM as an evaluation to evaluate the proposed model. This paper is organized as follows. Section I is an Introduction to the background of the problem, Section II introduces the process of the FDM to assess the expert consensus and lists the alternative options in the order of preference. Section III shows results and finding of an element in Hytee model. The conclusion of the research findings and future work of this research is presented in Section IV. The results are expected to provide an element to support in design and development of Hytee Model.

\section{FUZZY DELPHI METHOD}

\section{A. Introduction}

This research study is about implementing the Fuzzy Delphi Method in designing and developing a software traceability model with the test effort estimation during regression testing in software changes. The Delphi Method is an approach that has been used and widely accepted to collect data for a study based on the validation expert in the research study of Hsu [8]. The strength of this method has also produced a diversity technique in obtaining empirical data like the Fuzzy Delphi Method (FDM). Talking about FDM, it is a method of measurement based on the modification on the Delphi Method.

This method has been presented by Kaufman and Gupta in 1988 [9]. The Fuzzy Delphi Method (FDM) is a combination of the numbering of the fuzzy set method and Delphi itself [10]. This brings the meaning that this is not a new approach based on a classical Delphi method where the respondents involved must be from within the circle of experts who have experience in the context of the study. This improvement indirectly strives to make FDM as a measurement approach that is more effective, whereby FDM is able to resolve the issue of who has uncertainty for some issues of the research.

The review of previous literature shows that FDM is a combination of the traditional method of Delphi (Classic) and fuzzy set theory (Fuzzy). The fuzzy set theory was introduced by an expert in the field of mathematics in 1965 which Zadeh [11] worked, and it works as an extension of a classical set theory where each element in a set is assessed based on the set of binaries (Yes or No). Fuzzy set theory assessment also allows a gradual review of each element. Ragin [12] states that the value of numbering fuzzy consists of 0 to 1 or in the unit interval $(0,1)$.

There are two mains in FDM which is Triangular Fuzzy Number and Defuzzification Process. Triangular Fuzzy Number is $\mathrm{m}$ is made up of the value of the $\mathrm{m} 1, \mathrm{~m} 2$, and $\mathrm{m} 3$ where $\mathrm{m} 1$ represents the value of the minimum (smallest value), representing the most reasonable value $\mathrm{m} 2$ (most plausible value) and $\mathrm{m} 3$ is referring to the maximum value (but there is value). All three values in the Triangular Fuzzy Number this can be seen through Fig. 2 shows the graph that triangles mean against the value of triangular shows that all three of these values is also in the range of 0 to 1 and it coincided with fuzzy numbers [12].

\section{B. Procedure in FDM}

For further details on the findings using the Fuzzy Delphi approach method (FDM), there are procedures that must be compiled. Table I show about the procedures in FDM cover for seven steps.

\section{The Number of Expect in FDM}

The selection of the number of experts for the Fuzzy Delphi Method (FDM) is a total of 12 people. This is based on the view of Adler and Ziglio [13], who pointed out that the number of experts for the Delphi technique was as many as 10 to 15 people if the experts can get an agreement with each other. However, there is also an opinion stating that the minimum number of experts for the Delphi technique is five experts [14]. This matches the argument from Rowe and Wright [15] that the number of experts can start from 5 to 20 people based on their areas of expertise. On the other hand, Jones and Twiss [16] suggested the number of experts involved in the Delphi method approach is 10 to 50 experts.

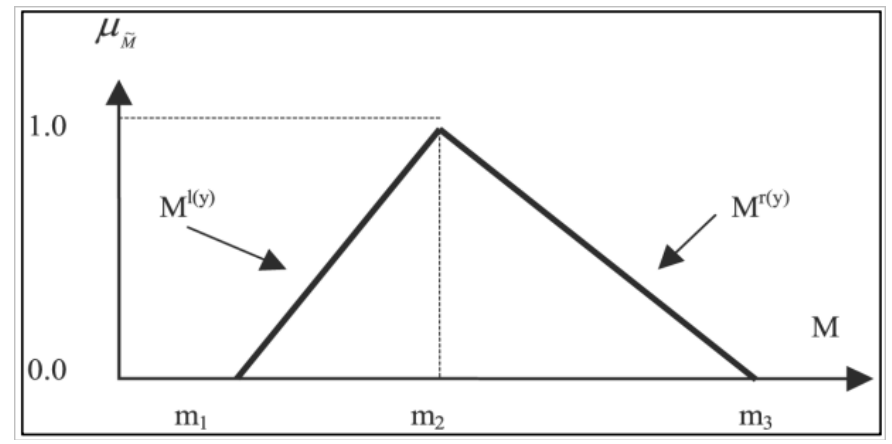

Fig. 2. Graph Triangle Min against the Value of Triangular.

TABLE I. PROCEDURES IN FDM

\begin{tabular}{|l|l|}
\hline Step & Detail \\
\hline 1 & $\begin{array}{l}\text { Criteria to determine the experts involved in the study. } \\
\text { Expert in FDM }\end{array} \quad \begin{array}{l}10-15 \text { expert (Adler \&Ziglo, 1996) } \\
10-50 \text { expert (Jones \& Twiss, 1978) }\end{array}$ \\
\hline 2 & $\begin{array}{l}\text { Convert all linguistic variables into a triangular fuzzy number } \\
\text { All data is scheduled to obtain the average value (m1, m2, m3) }\end{array}$ \\
\hline 4 & $\begin{array}{l}\text { Determine the distance between the 2 numbers fuzzy to determine } \\
\text { the value of the threshold, } \\
\mathrm{d} \leq 0.2, \text { meaning that all the experts reach consensus. }\end{array}$ \\
\hline 5 & $\begin{array}{l}\text { Determine the consensus of the Group } \\
\text { Value of the percent agreement of experts that must be equal } \\
\text { to or more than } 75.0 \%\end{array}$ \\
\hline 6 & $\begin{array}{l}\text { Define Aggregate Fuzzy Evaluation by adding all fuzzy numbers } \\
\text { Data analysis using the average of fuzzy numbers or average } \\
\text { response (Defuzzification Process) }\end{array}$ \\
\hline 7
\end{tabular}


The criteria and characteristics of this study involved software engineering specialists in software testing from the academic and industrial sector. Selection is also based on Berliner [17],[18] who argues that the expert is competent if they participated in a particular field consistently exceeding a period of 5 years. Nonetheless, there are other scholars pointing out that experts are highly skilled and experienced in the areas studied [19][20].

Based on Table II, the discussion for selection of the respondents for the design and development phase, the researcher lists down the criteria for selecting the experts, as below:

\section{Questionnaire}

This research uses the questionnaire as an instrument to get quantitative data for element requirements of Hytee Model. The questionnaire is aimed at in order to meet the criteria and conditions of the using the technique of fuzzy Delphi Method where this technique involves the use of a mathematical formula in order to obtain the consensus of experts. Instruments used by researchers is the instrument that has been modified based on the needs of the study researchers. The original of this questionnaire was adapted from the study of Ibrahim (2006) [21]. Table III shows the element in the questionnaire.

The process of data collection in the study is carried out using the Fuzzy Delphi approach between the processes involved in an interview for the Delphi technique while the questionnaire is analyzed with techniques of a fuzzy number. 5-point scale used Rahman, M. N. A. (2013) [23] to determine the expected kinds of video games against aspects of basic skills in the Malay language for foreign students to obtain consent or consensus of a group of expert. To facilitate experts, answer questionnaires, researchers have put the value of the scale of 1 to 5 to replace the Fuzzy value as shown in Table IV for linguistic scale 5 points follows;

TABLE II. ClassificATION OF HETEROGENEOUS EXPERTS

\begin{tabular}{|l|l|l|}
\hline \multirow{5}{*}{ Expert } & Background & $\begin{array}{l}\text { Number of } \\
\text { Participants }\end{array}$ \\
\hline \multirow{5}{*}{ Industry } & Public Bank (System Analyst) & 1 \\
\cline { 2 - 3 } & Iris Berhad (It support) & 2 \\
\cline { 2 - 3 } & $\begin{array}{l}\text { Mimos Berhad (Software } \\
\text { Tester) }\end{array}$ & 2 \\
\cline { 2 - 3 } & Mesiniaga (It Engineer) & 2 \\
\hline \multirow{3}{*}{ Academicians } & It Officer (KPKT) & 1 \\
\cline { 2 - 3 } & It Officer (LGM) & 1 \\
\cline { 2 - 3 } & It Officer (MBPP) & 1 \\
\hline Total & Pecture It ( Polytechnic & 2 \\
\hline
\end{tabular}

TABLE III. QUESTIONNAIRE IN FDM

\begin{tabular}{|c|c|c|}
\hline Section & Element & Questionnaire \\
\hline B & $\begin{array}{l}\text { Change } \\
\text { Management }\end{array}$ & $\begin{array}{l}\text { B1: Do you agree that Hytee model support } \\
\text { change management of software artifact? } \\
\text { B2: Do you agree that change management } \\
\text { support will help to save time? } \\
\text { B3: Do you agree that Hytee model can help the } \\
\text { current practice in after getting PCR } \\
\text { B4: Do you agree that Hytee model provide } \\
\text { appropriates content } \\
\text { B5: Do you agree that Hytee model that the } \\
\text { system and process developed to achieve the } \\
\text { change are transparent }\end{array}$ \\
\hline $\mathrm{C}$ & $\begin{array}{l}\text { Traceability } \\
\text { Support }\end{array}$ & $\begin{array}{l}\text { C1: Do you agree that Hytee model provide } \\
\text { traceability for requirement, test cases, and code } \\
\text { C2: Do you agree that Hytee model it is easy to } \\
\text { create traceability link between artifact } \\
\text { C3: Do you agree that Hytee model it easy to } \\
\text { locate test cases to the requirement or vice versa } \\
\text { C4: Do you agree that developers get a benefit } \\
\text { from requirements traceability when evolving } \\
\text { and maintaining a software system? } \\
\text { C5: Do you agree that Hytee model using top - } \\
\text { bottom and bottom to up will help to find the } \\
\text { bug? }\end{array}$ \\
\hline D & $\begin{array}{l}\text { Regression } \\
\text { Testing } \\
\text { Support }\end{array}$ & $\begin{array}{l}\text { D1: Do you agree that Hytee model in } \\
\text { regression testing provide the helpful function } \\
\text { D2: Do you agree that Hytee model of RT } \\
\text { function will help the user to save a time } \\
\text { D3: Do you agree that Hytee model can help the } \\
\text { current practice during RT } \\
\text { D4: Do you agree that Hytee model provide } \\
\text { appropriates content }\end{array}$ \\
\hline E & $\begin{array}{l}\text { Test Effort } \\
\text { Estimation } \\
\text { Support }\end{array}$ & $\begin{array}{l}\text { E1: Do you agree that Hytee model provides a } \\
\text { basis to cost estimation and plan schedules } \\
\text { E2: Do you agree that Hytee model in test effort } \\
\text { estimation support will help the user to estimate } \\
\text { the cost after changes. } \\
\text { E3: Do you agree that Hytee model in test effort } \\
\text { estimation support provide appropriates content } \\
\text { E4: Do you agree that Hytee model in test effort } \\
\text { estimation support help the user save time } \\
\text { /cost/skill } \\
\text { E5: Do you agree that Hytee model in test effort } \\
\text { estimation support will reduce situational and } \\
\text { human biases }\end{array}$ \\
\hline F & Report & $\begin{array}{l}\text { F1: Do you agree that Hytee model produced the } \\
\text { report is helpful } \\
\text { F2: Do you agree that Hytee model provide the } \\
\text { reports be invoked which identify the fields } \\
\text { which have been modified } \\
\text { F3: Do you agree that Hytee model these reports } \\
\text { provide a complete record of all such changes }\end{array}$ \\
\hline G & GUI & $\begin{array}{l}\text { G1: Do you agree that Hytee model is user- } \\
\text { friendly } \\
\text { G2: Do you agree that Hytee model which the } \\
\text { term in the prototype understandable } \\
\text { G3: It helps me be more effective } \\
\text { G4: Do you agree that Hytee model organization } \\
\text { of information very clear }\end{array}$ \\
\hline
\end{tabular}


TABLE IV. LINGUISTIC VARIABLES FOR 5 POINT SCALE

\begin{tabular}{|l|l|l|}
\hline Linguistic Variables & Likert Scale & Fuzzy Scale \\
\hline Strongly agree & 5 & $(0.9,1.0,1.0)$ \\
\hline Agree & 4 & $(0.5,0.7,0.9)$ \\
\hline Neither agree & 3 & $(0.3,0.5,0.7)$ \\
\hline Disagree & 2 & $(0.1,0.3,0.5)$ \\
\hline Strongly disagree & 1 & $(0.0,0.0,0.1)$ \\
\hline
\end{tabular}

\section{RESULT AND FINDING}

Data analysis is to follow the approach of Fuzzy $\backslash$ Delphi through step 3 to 7 will answer questions the study disclosed. For viewing the degree of agreement among experts, the findings for each of the items were analyzed by a Threshold value (d) for two fuzzy numbers $\mathrm{m}=(\mathrm{m} 1, \mathrm{~m} 2, \mathrm{~m} 3)$ and $\mathrm{n}=$ $(\mathrm{m} 1, \mathrm{~m} 2, \mathrm{~m} 3)$ are calculated using the formula:

$d=\widetilde{m}, \tilde{n} \sqrt{\frac{1}{3}\left[\left(m_{1}-n_{1}\right)^{2}+\left(m_{2}-n_{2}\right)^{2}+\left(m_{3}-n_{3}\right)^{2}\right]}$

It is supported by the Rahman, 2013 [22] and Jamil, 2013 [23] which States that in order to analyze the data, the distance between two Fuzzy number is calculated by measuring the average value of the deviation between the experts. Whereas the criteria used to assess the expert group consensus is based on the degree of agreement in excess of $75 \%$.

In this study, one (1) is complied with because the value threshold for most of the subitem is $\leq 0.2$, but only at part subitem only. However, the second condition (2) has also been observed because the expert group consensus is above $75 \%$. Result value threshold $\leq 0.2$, indicating that this study gets the value of the threshold exceeds $75 \% 77.8 \%$ by registering for a theme that includes a total of 5 subitems. This shows the degree of agreement among the experts has reached a consensus that good. Therefore, the second round for fuzzy Delphi is not needed because of data acquisition complies with both conditions.

Below show the findings for elements of Hytee model based on the consensus of experts. This data consists of the value of the threshold each element ( $d$ item), the value threshold constructs $(\mathrm{d})$

\section{A. Change Management}

Table $\mathrm{V}$ display findings for Change Management components for Hytee proposed model on the consensus of experts using the Fuzzy Delphi Method (FDM). The findings of this study show the value threshold (d) and the percentage of the expert group.

\section{B. Traceability Support}

Table VI display findings for Traceability Support components for Hytee proposed model on the consensus of experts using the Fuzzy Delphi Method (FDM). The findings of this study show the value threshold (d) and the percentage of the expert group.
TABLE V. Change MANAGEMENT COMPONENTS

\begin{tabular}{|l|l|l|l|l|l|l|}
\hline \multicolumn{2}{|l}{ EXPERT } & \multicolumn{5}{l}{ Change Management } \\
\cline { 3 - 7 } & B1 & B2 & B3 & B4 & B5 \\
\hline 1 & Expert 1 & 0.131 & 0.239 & 0.120 & 0.370 & 0.098 \\
\hline 2 & Expert 2 & 0.261 & 0.154 & 0.275 & 0.076 & 0.098 \\
\hline 3 & Expert 3 & 0.261 & 0.154 & 0.275 & 0.317 & 0.294 \\
\hline 4 & Expert 4 & 0.131 & 0.154 & 0.275 & 0.076 & 0.098 \\
\hline 5 & Expert 5 & 0.131 & 0.526 & 0.709 & 0.076 & 0.098 \\
\hline 6 & Expert 6 & 0.261 & 0.154 & 0.275 & 0.317 & 0.294 \\
\hline 7 & Expert 7 & 0.131 & 0.239 & 0.120 & 0.076 & 0.098 \\
\hline 8 & Expert 8 & 0.131 & 0.154 & 0.120 & 0.076 & 0.098 \\
\hline 9 & Expert 9 & 0.131 & 0.154 & 0.120 & 0.076 & 0.098 \\
\hline 10 & Expert 10 & 0.261 & 0.154 & 0.275 & 0.317 & 0.294 \\
\hline 11 & Expert 11 & 0.131 & 0.239 & 0.120 & 0.076 & 0.098 \\
\hline 12 & Expert 12 & 0.131 & 0.154 & 0.120 & 0.076 & 0.098 \\
\hline $\begin{array}{l}\text { Threshold Value } \\
\text { (d) of each item }\end{array}$ & 0.174 & 0.206 & 0.234 & 0.161 & 0.147 \\
\hline $\begin{array}{l}\text { The percentage of } \\
\text { each item d } \leq 0.2\end{array}$ & 100.0 & 91.7 & 91.7 & 66.7 & 100.0 \\
\hline $\begin{array}{l}\text { Average of fuzzy } \\
\text { number (score } \\
\text { fuzzy) }\end{array}$ & 0.789 & 0.861 & 0.778 & 0.750 & 0.767 \\
\hline
\end{tabular}

TABLE VI. TRACEABILITY SUPPORT COMPONENTS

\begin{tabular}{|l|l|l|l|l|l|l|}
\hline \multicolumn{2}{|l}{ EXPERT } & \multicolumn{5}{l}{ Traceability Support } \\
\cline { 3 - 7 } & C1 & C2 & C3 & C4 & C5 \\
\hline 1 & Expert 1 & 0.186 & 0.261 & 0.196 & 0.261 & 0.163 \\
\hline 2 & Expert 2 & 0.186 & 0.131 & 0.196 & 0.131 & 0.228 \\
\hline 3 & Expert 3 & 0.186 & 0.131 & 0.196 & 0.261 & 0.163 \\
\hline 4 & Expert 4 & 0.186 & 0.131 & 0.196 & 0.131 & 0.228 \\
\hline 5 & Expert 5 & 0.495 & 0.261 & 0.196 & 0.131 & 0.163 \\
\hline 6 & Expert 6 & 0.206 & 0.131 & 0.196 & 0.131 & 0.163 \\
\hline 7 & Expert 7 & 0.206 & 0.261 & 0.196 & 0.261 & 0.163 \\
\hline 8 & Expert 8 & 0.186 & 0.131 & 0.196 & 0.131 & 0.228 \\
\hline 9 & Expert 9 & 0.186 & 0.131 & 0.196 & 0.131 & 0.228 \\
\hline 10 & Expert 10 & 0.206 & 0.131 & 0.196 & 0.131 & 0.163 \\
\hline 11 & Expert 11 & 0.206 & 0.261 & 0.196 & 0.261 & 0.163 \\
\hline 12 & Expert 12 & 0.186 & 0.131 & 0.196 & 0.131 & 0.228 \\
\hline $\begin{array}{l}\text { Threshold Value } \\
\text { (d) of each item }\end{array}$ & 0.219 & 0.174 & 0.196 & 0.174 & 0.190 \\
\hline $\begin{array}{l}\text { The percentage of } \\
\text { each item d } \leq 0.2\end{array}$ & $91.7 \%$ & $100.0 \%$ & $100.0 \%$ & $100.0 \%$ & $100.0 \%$ \\
\hline $\begin{array}{l}\text { Average of fuzzy } \\
\text { number (score } \\
\text { fuzzy) }\end{array}$ & 0.839 & 0.878 & 0.833 & 0.878 & 0.811 \\
\hline
\end{tabular}




\section{Regression Testing Support}

Table VII display findings for Regression Testing Support components for Hytee proposed model on the consensus of experts using the Fuzzy Delphi Method (FDM). The findings of this study show the value threshold (d) and the percentage of the expert group.

\section{Test Effort Estimation Support}

Table VIII display findings for Test Effort Estimation Support components for Hytee proposed model on the consensus of experts using the Fuzzy Delphi Method (FDM). The findings of this study show the value threshold (d) and the percentage of the expert group.

TABLE VII. REGRESSION TESTING SUPPORT COMPONENTS

\begin{tabular}{|l|l|l|l|l|l|}
\hline \multirow{2}{*}{ EXPERT } & \multicolumn{4}{l}{ Regression Testing Support } \\
\cline { 3 - 6 } \multicolumn{2}{|l}{} & D1 & D2 & D3 & D4 \\
\hline 1 & Expert 1 & 0.065 & 0.249 & 0.141 & 0.108 \\
\hline 2 & Expert 2 & 0.326 & 0.145 & 0.251 & 0.284 \\
\hline 3 & Expert 3 & 0.065 & 0.249 & 0.141 & 0.108 \\
\hline 4 & Expert 4 & 0.326 & 0.145 & 0.141 & 0.108 \\
\hline 5 & Expert 5 & 0.065 & 0.833 & 0.432 & 0.401 \\
\hline 6 & Expert 6 & 0.065 & 0.145 & 0.251 & 0.108 \\
\hline 7 & Expert 7 & 0.065 & 0.145 & 0.251 & 0.108 \\
\hline 8 & Expert 8 & 0.065 & 0.145 & 0.141 & 0.284 \\
\hline 9 & Expert 9 & 0.065 & 0.145 & 0.141 & 0.284 \\
\hline 10 & Expert 10 & 0.065 & 0.145 & 0.251 & 0.108 \\
\hline 11 & Expert 11 & 0.065 & 0.145 & 0.251 & 0.108 \\
\hline 12 & Expert 12 & 0.065 & 0.145 & 0.141 & 0.284 \\
\hline $\begin{array}{l}\text { Threshold Value (d) } \\
\text { of each item }\end{array}$ & 0.109 & 0.220 & 0.211 & 0.191 \\
\hline $\begin{array}{l}\text { The percentage of } \\
\text { each item d } 0.2\end{array}$ & $83.3 \%$ & $91.7 \%$ & $91.7 \%$ & $91.7 \%$ \\
\hline $\begin{array}{l}\text { Average of fuzzy } \\
\text { number (score fuzzy) }\end{array}$ & 0.744 & 0.867 & 0.794 & 0.772 \\
\hline
\end{tabular}

TABLE VIII. TEST EFFORT ESTIMATION SUPPORT COMPONENTS

\begin{tabular}{|l|l|l|l|l|l|l|}
\hline \multirow{2}{*}{ EXPERT } & \multicolumn{5}{l}{ Test Effort Estimation Support } \\
\cline { 3 - 7 } \multicolumn{2}{|l|l|l|l|l|l|}{} & E1 & E2 & E3 & E4 & E5 \\
\hline 1 & Expert 1 & 0.196 & 0.261 & 0.108 & 0.239 & 0.173 \\
\hline 2 & Expert 2 & 0.196 & 0.131 & 0.284 & 0.154 & 0.219 \\
\hline 3 & Expert 3 & 0.196 & 0.261 & 0.108 & 0.239 & 0.463 \\
\hline 4 & Expert 4 & 0.196 & 0.261 & 0.108 & 0.239 & 0.173 \\
\hline 5 & Expert 5 & 0.196 & 0.261 & 0.401 & 0.526 & 0.173 \\
\hline 6 & Expert 6 & 0.196 & 0.131 & 0.108 & 0.154 & 0.219 \\
\hline 7 & Expert 7 & 0.196 & 0.131 & 0.108 & 0.154 & 0.173 \\
\hline 8 & Expert 8 & 0.196 & 0.131 & 0.284 & 0.154 & 0.219 \\
\hline 9 & Expert 9 & 0.196 & 0.131 & 0.284 & 0.154 & 0.219 \\
\hline 10 & Expert 10 & 0.196 & 0.131 & 0.108 & 0.154 & 0.219 \\
\hline 11 & Expert 11 & 0.196 & 0.131 & 0.108 & 0.154 & 0.173 \\
\hline 12 & Expert 12 & 0.196 & 0.131 & 0.284 & 0.154 & 0.219 \\
\hline $\begin{array}{l}\text { Threshold Value } \\
\text { (d) of each item }\end{array}$ & 0.196 & 0.174 & 0.191 & 0.206 & 0.220 \\
\hline $\begin{array}{l}\text { The percentage of } \\
\text { each item d } \leq 0.2\end{array}$ & $100.0 \%$ & $100.0 \%$ & $91.67 \%$ & $91.67 \%$ & $91.67 \%$ \\
\hline $\begin{array}{l}\text { Average of fuzzy } \\
\text { number (score } \\
\text { fuzzy) }\end{array}$ & 0.833 & 0.878 & 0.772 & 0.861 & 0.817 \\
\hline
\end{tabular}

\section{E. Report}

Table IX display findings for Report components for Hytee proposed model on the consensus of experts using the Fuzzy Delphi Method (FDM). The findings of this study show the value threshold (d) and the percentage of the expert group.

\section{F. Graphical user Interface}

Table X display findings for Graphical User Interface components for Hytee proposed model on the consensus of experts using the Fuzzy Delphi Method (FDM). The findings of this study show the value threshold (d) and the percentage of the expert group.

TABLE IX. Report COMPONENTS

\begin{tabular}{|l|l|l|l|l|}
\hline \multicolumn{2}{|l|}{ EXPERT } & \multicolumn{2}{l}{ Report } \\
\cline { 3 - 5 } \multicolumn{2}{|l|}{} & F1 & F2 & F3 \\
\hline 1 & Expert 1 & 0.294 & 0.076 & 0.015 \\
\hline 2 & Expert 2 & 0.098 & 0.317 & 0.382 \\
\hline 3 & Expert 3 & 0.294 & 0.076 & 0.015 \\
\hline 4 & Expert 4 & 0.098 & 0.076 & 0.015 \\
\hline 5 & Expert 5 & 0.294 & 0.370 & 0.309 \\
\hline 6 & Expert 6 & 0.098 & 0.076 & 0.015 \\
\hline 7 & Expert 7 & 0.098 & 0.317 & 0.015 \\
\hline 8 & Expert 8 & 0.098 & 0.076 & 0.015 \\
\hline 9 & Expert 9 & 0.098 & 0.076 & 0.015 \\
\hline 10 & Expert 10 & 0.098 & 0.076 & 0.015 \\
\hline 11 & Expert 11 & 0.098 & 0.317 & 0.015 \\
\hline 12 & Expert 12 & 0.098 & 0.076 & 0.015 \\
\hline $\begin{array}{l}\text { Threshold Value (d) of } \\
\text { each item }\end{array}$ & 0.147 & 0.161 & 0.070 \\
\hline $\begin{array}{l}\text { The percentage of each } \\
\text { item d } \leq 0.2\end{array}$ & $100.0 \%$ & $66.67 \%$ & $83.33 \%$ \\
\hline $\begin{array}{l}\text { Average of fuzzy number } \\
\text { (score fuzzy) }\end{array}$ & 0.900 & 0.750 & 0.706 \\
\hline
\end{tabular}

TABLE X. GRAPHICAL USER INTERFACE COMPONENTS

\begin{tabular}{|l|l|l|l|l|l|}
\hline \multicolumn{2}{|l}{ EXPERT } & \multicolumn{4}{l}{ Graphical user Interface } \\
\cline { 3 - 6 } & G1 & G2 & G3 & G4 \\
\hline 1 & Expert 1 & 0.141 & 0.261 & 0.239 & 0.108 \\
\hline 2 & Expert 2 & 0.251 & 0.131 & 0.154 & 0.284 \\
\hline 3 & Expert 3 & 0.251 & 0.131 & 0.154 & 0.284 \\
\hline 4 & Expert 4 & 0.141 & 0.131 & 0.154 & 0.108 \\
\hline 5 & Expert 5 & 0.432 & 0.261 & 0.526 & 0.401 \\
\hline 6 & Expert 6 & 0.141 & 0.131 & 0.154 & 0.108 \\
\hline 7 & Expert 7 & 0.141 & 0.261 & 0.239 & 0.284 \\
\hline 8 & Expert 8 & 0.251 & 0.131 & 0.154 & 0.108 \\
\hline 9 & Expert 9 & 0.251 & 0.131 & 0.154 & 0.108 \\
\hline 10 & Expert 10 & 0.141 & 0.131 & 0.154 & 0.108 \\
\hline 11 & Expert 11 & 0.141 & 0.261 & 0.239 & 0.284 \\
\hline 12 & Expert 12 & 0.251 & 0.131 & 0.154 & 0.108 \\
\hline $\begin{array}{l}\text { Threshold Value (d) } \\
\text { of each item }\end{array}$ & 0.211 & 0.174 & 0.206 & 0.191 \\
\hline $\begin{array}{l}\text { The percentage of } \\
\text { each item d } \leq 0.2\end{array}$ & $91.67 \%$ & $100.0 \%$ & $91.67 \%$ & $91.67 \%$ \\
\hline $\begin{array}{l}\text { Average of fuzzy } \\
\text { number (score } \\
\text { fuzzy) }\end{array}$ & 0.794 & 0.878 & 0.861 & 0.772 \\
\hline
\end{tabular}




\section{G. Result Consensus of the Expert}

Requirement:

1) Triangular Fuzzy Numbers

a) Threshold value, $\mathrm{d}<0.2$

b) Percentage of Consensus Expert Group, $\% \geq 75.0 \%$

2) Defuzzification Process

a) Score Fuzzy (A) $\geq$ Value $\alpha-$ cut $=0.5$

Refer to Table XI, the Fuzzy Delphi Analysis of the present study has shown a satisfactory and good overall outcome.
From the findings, all the item meets the expert consensus $\geq$ $75.0 \%$. The first two elements, in change management and the report, has an average value of "d" threshold of less than 0.2. Accordingly, both have reached the percentage of expert consensus of more than $75 \%$, and the defuzzification scores greater than 0.5 , making them acceptable as antecedents for the customer engagement concept studied. This study for evaluation Hytee Model 2 item needs to revise again and update in the Hytee System. That action was done to able the whole $\%$ item "d" $\leq 0.2$ has achieved the agreement of $78 \%$, making this construct successfully maintained.

TABLE XI. RESULT OF A CONSENSUS OF THE EXPECT

\begin{tabular}{|c|c|c|c|c|c|c|c|c|}
\hline & & Triangular Fuz & mbers & Defuz & ication & & & \\
\hline & ement & & Percentage of & & & & & Experts \\
\hline 1 & B1 & 0.174 & $100.0 \%$ & 0.633 & 0.800 & 0.933 & 0.789 & ACCEPT \\
\hline 2 & B2 & 0.206 & $91.7 \%$ & 0.750 & 0.883 & 0.950 & 0.861 & ACCEPT \\
\hline 3 & B3 & 0.234 & $91.7 \%$ & 0.633 & 0.792 & 0.908 & 0.778 & АCCEPT \\
\hline 4 & B4 & 0.161 & $66.67 \%$ & 0.583 & 0.758 & 0.908 & 0.750 & REJECT \\
\hline 5 & B5 & 0.147 & $100.00 \%$ & 0.600 & 0.775 & 0.925 & 0.767 & ACCEPT \\
\hline 6 & $\mathrm{C} 1$ & 0.219 & $91.67 \%$ & 0.717 & 0.858 & 0.942 & 0.839 & ACCEPT \\
\hline 7 & $\mathrm{C} 2$ & 0.174 & $100.00 \%$ & 0.767 & 0.900 & 0.967 & 0.878 & ACCEPT \\
\hline 8 & $\mathrm{C} 3$ & 0.196 & $100.00 \%$ & 0.700 & 0.850 & 0.950 & 0.833 & ACCEPT \\
\hline 9 & $\mathrm{C} 4$ & 0.174 & $100.00 \%$ & 0.767 & 0.900 & 0.967 & 0.878 & ACCEPT \\
\hline 10 & $\mathrm{C} 5$ & 0.190 & $100.00 \%$ & 0.667 & 0.825 & 0.942 & 0.811 & ACCEPT \\
\hline 11 & D1 & 0.109 & $83.33 \%$ & 0.567 & 0.750 & 0.917 & 0.744 & ACCEPT \\
\hline 12 & D2 & 0.220 & $91.67 \%$ & 0.767 & 0.892 & 0.942 & 0.867 & ACCEPT \\
\hline 13 & D3 & 0.211 & $91.67 \%$ & 0.650 & 0.808 & 0.925 & 0.794 & ACCEPT \\
\hline 14 & D4 & 0.191 & $91.67 \%$ & 0.617 & 0.783 & 0.917 & 0.772 & ACCEPT \\
\hline 15 & E1 & 0.196 & $100.00 \%$ & 0.700 & 0.850 & 0.950 & 0.833 & ACCEPT \\
\hline 16 & E2 & 0.174 & $100.00 \%$ & 0.767 & 0.900 & 0.967 & 0.878 & ACCEPT \\
\hline 17 & E3 & 0.191 & $91.67 \%$ & 0.617 & 0.783 & 0.917 & 0.772 & ACCEPT \\
\hline 18 & E4 & 0.206 & $91.67 \%$ & 0.750 & 0.883 & 0.950 & 0.861 & ACCEPT \\
\hline 19 & E5 & 0.220 & $91.67 \%$ & 0.683 & 0.833 & 0.933 & 0.817 & ACCEPT \\
\hline 20 & $\mathrm{~F} 1$ & 0.147 & $100.00 \%$ & 0.800 & 0.925 & 0.975 & 0.900 & ACCEPT \\
\hline 21 & F2 & 0.161 & $66.67 \%$ & 0.583 & 0.758 & 0.908 & 0.750 & REJECT \\
\hline 22 & F3 & 0.070 & $83.33 \%$ & 0.517 & 0.708 & 0.892 & 0.706 & ACCEPT \\
\hline 23 & G1 & 0.211 & $91.67 \%$ & 0.650 & 0.808 & 0.925 & 0.794 & ACCEPT \\
\hline 24 & G2 & 0.174 & $100.00 \%$ & 0.767 & 0.900 & 0.967 & 0.878 & ACCEPT \\
\hline 25 & G3 & 0.206 & $91.67 \%$ & 0.750 & 0.883 & 0.950 & 0.861 & ACCEPT \\
\hline 26 & G4 & 0.191 & $91.67 \%$ & 0.617 & 0.783 & 0.917 & 0.772 & ACCEPT \\
\hline
\end{tabular}




\section{CONCLUSION AND FUTURE WORK}

It has concluded that all the elements in Hytee Model (except 2 elements) are maintained and certified of Hytee model based on the consensus of an expert. Using Fuzzy Delphi Method analysis, this study has proven the importance of element in Hytee Model. The findings of the study are in line with its purpose to answer the questions pertaining to the agreement of experts on an element into work developing proposed Hytee Model. The defuzzification process is greatly used to filter the priority of element. In change management, the contribution of this result to ensure the user understands the environment of change management. For traceability support the contribution of this study to prove the flow of the system using the traceability model. For regression testing support refer to Table VII is to show the function of regression testing in Hytee Model. In test effort estimation refer to Table VI show the user the result after all the flow of change of the error. For report and GUI refer to the table, we can see that the expert agree with the GUI of Hytee Model.

As future work, in this stage, the researcher will design the model based on the data from the Fuzzy Delphi Method discussion within the expert review. From elements of change management, traceability support, regression testing support, test effort estimation support, report and GUI, the findings it to continue to upgrade the proposed model to the actual model for improvement.

\section{REFERENCES}

[1] Vasa, R., Schneider, J. G., \& Nierstrasz, O. (2007, October). The inevitable stability of software change. In Software Maintenance, 2007. ICSM 2007. IEEE International Conference on (pp. 4-13). IEEE.

[2] The Standish Group, Chaos, Standish Group Report, 2004

[3] Lam, W., \& Shankararaman, V. (1999). Requirements change a dissection of management issues. In EUROMICRO Conference, 1999. Proceedings. 25th (Vol. 2, pp. 244-251). IEEE

[4] Nurmuliani, N., Zowghi, D., \& Powell, S. (2004). Analysis of requirements volatility during the software development lifecycle. In Software Engineering Conference, 2004. Proceedings. 2004 Australian (pp. 28-37). IEEE.

[5] The Standish Group, Chaos, Standish Group Report, 2015

[6] Bertolino, A. (2007, May). Software testing research: Achievements, challenges, dreams. In 2007 Future of Software Engineering (pp. 85103). IEEE Computer Society.

[7] Aranha, E., \& Borba, P. (2007, September). An estimation model for test execution effort. In Empirical Software Engineering and Measurement, 2007. ESEM 2007. First International Symposium on (pp. 107-116). IEEE
[8] Hsu, C. C., \& Sandford, B. A. (2007). The Delphi technique: making sense of consensus. Practical assessment, research \& evaluation, 12(10), $1-8$

[9] Kaufmann, A., \& Gupta, M. M. (1988). Fuzzy mathematical models in engineering and management science. Elsevier Science Inc.

[10] Murray, T., Pipino, L., \& Vangigch, J. (1985). A pilot study of Fuzzy set modification of Delphi. Human-System Management, 5(1), 6-80.

[11] Zadeh L.A. (1965). Fuzzy sets and systems, System Theory (Fox J., ed.), Microwave Research Institute Symposia Series XV, Polytechnic Press, Brooklyn, NY, 29- 37. Reprinted in Int. J. of General Systems, 17, 1990, 129-138

[12] Ragin, C. C. (2007). Qualitative comparative analysis using fuzzy sets (fsQCA). In Configurational comparative analysis. London: Sage Publications.

[13] Adler, M., \& Ziglio, E. (1996). Gazing into the oracle: the Delphi method and its application to social policy and public health. London: Jessica Kingsley Publishers

[14] Mahmud, R., Ismail, M. A., Mustapha, R., Din, R., \& Yasin, R. M. (2006). Information and Communication Technology (ICT) Readiness among Malaysian Secondary School Teachers. Asia-Pacific Collaborative Education Journal, 2(1), 9-15.

[15] Rowe, G., \& Wright, G. (2011). The Delphi technique: Past, present, and future prospects - Introduction to the special issue. Technological Forecasting and Social Change, 78(9), 1487-1490

[16] Jones, H. \& Twiss, B.L. (1978). Forecasting Technology For Planning Decisions. New York: Macmillan

[17] Berliner, D. C. (2004). Expert teachers: Their characteristics, development, and accomplishments. Bulletin of Science, Technology and Society, 24(3), 200-212.

[18] Berliner, D. C. (2004). Describing the behavior and documenting the accomplishments of expert teachers. Bulletin of Science, Technology \& Society, 24(3), 200-212.

[19] Swanson, R. A., \& Falkman, S. K. (1997). Training delivery problems and solutions: Identification of novice trainer problems and expert trainer solutions. Human Resource Development Quarterly, 8(4), 305314.

[20] Dalkey, N. C., \& Helmer, O. (1963). An experimental application of the Delphi method to the use of experts. Management Science, 9(3), 458467

[21] Ibrahim, S. (2006). A Document-based Software Traceability to Support Change Impact Analysis of Object-oriented Software(Doctoral dissertation, Universiti Teknologi Malaysia).

[22] Rahman, M. N. A. (2013). Norlidah Alias, Saedah Siraj \& Dorothy Dewitt. Model Homeschooling Berasaskan Teknologi di Malaysia: Pendekatan Interpretive Structural Modeling.Mohd.

[23] Jamil, M. R. M., Hussin, Z., Noh, N. R. M., Sapar, A. A., \& Alias, N. (2013). Application of Fuzzy Delphi Method in educational research. Saedah Siraj, Norlidah Alias, DeWitt, D. \& Zaharah Hussin (Eds.), Design and developmental research, 85-92. 